4. Dorylas Thomsoni Beck. (Pipunculus) Berl. Ent. Zeitschr. XLII, 67. 29. Tab. II, Fig. 18 (1897).

Die Synonymie dieser Art ergibt sich aus vorstehendem wie folgt:

Dorylas Thomsoni Beck.

campestris Schin. (nec Latr.) (1862).

pratorum Fall. p.p. (1816).

pratorum Zett. (1824).

pratorum Verrall (1901).

Die Art fascipes Zett. ist ferner als selbständige Art einzuziehen; dahingegen bleibt die Art fuscipes Zett. $\sigma^{x}$ bestehen, da nur das Weibchen als zu pratorum Fall. gehörig anzusehen ist.

\title{
Cis (Eridaulus) lineatocribratus Mell. v. Matchanus nov.
}

Von Edm. Reitter in Paskau (Mähren).

Von der Stammform durch die Skulptur der Flügeldecken auffallend verschieden. Während bei der Stammform die Punktreihen grob und tief und die Zwischenräume nur von wenigen, kaum sichtbaren Pünktchen besetzt sind und meist glatt erscheinen, sind die Punktreihen bei v. Matchanus etwas schwächer und seichter ausgeprägt, die Zwischenräume aber dicht und fein punktiert. Dadurch nähert sich die Skulptur der Flügeldecken mehr jener von Jaquemarti Mell. und nitidus Hbst., aber bei diesen Arten sind die gröberen Punkte nichtdeutlich gereiht. Das ơ von v. Matchanus hat den Clypeus schärfer 2 zähnig als die Stammform. Der große, gewölbte. seitlich gerundete Halsschild, dessen Seitenrandung von oben nicht sichtbar ist, läßt die Zugehörigkeit der neuen Form zu lineatocribratus erkennen.

Ich erhielt Stücke von Č elič (Nordbosnien), von Herrn Oberleutnant Jar. Matcha gesammelt und von Professor Z oufal eingesandt. Ferner fand ich unter meinem Materiale diese Form auch aus Rumänien, Kaukasus (Tbatani) und vom Talysch-Gebirge (am Kaspischen Meere).

\section{Cartodere (Cart. s. str. $^{1}$ ) subcostella n. sp.}

Von Edm. Reitter in Paskau (Mähren).

Der C. filiformis Gyll. zunächst verwandt, mit dieser fast übereinstimmend, den kleinen Stücken derselben in Form und Größe gleich, aber die Naht und alle abwechselnden, ungeraden, sehr schmalen Zwischenräume der sehr gedrängten groben Punktstreifen fein kielförmig erhöht; die Fühler sind ein wenig dünner, die mittleren Glieder aber kugelig, nicht länger als breit und die Keule etwas größer und stärker abgesetzt.

Durch die abwechselnd erhöhten Zwischenräume der Flügeldecken ist diese Art auch mit $C$. costulata Reitt. nahe verwandt; letztere ist aber in der Regel etwas größer, die Flügeldecken sind weniger parallel und haben an den Seiten dicht vor der Mitte einen tiefen Eindruck, der Halsschild ist feiner punktiert und die Fühler sind länger, dünner, die Keule schlanker, ihr erstes Glied sowie die Mittelglieder merklich länger als breit.

Ich besitze einige Exemplare aus Griechenland (Parnaß). Wahrscheinlich gehören alle Stücke von dieser Provenienz, die als filiformis bestimmt wurden, zu dieser Art.

1) Vide: Reitter, Fauna germanica III, p. 84. 


\section{$2 \mathrm{BHL}$ Biodiversity Heritage Library}

Reitter, Edmund. 1915. "Cis (Eridaulus) lineatocribratus MELL. v. Matchanus nov." Wiener entomologische Zeitung 34, 66.

https://doi.org/10.5962/bhl.part.10591.

View This Item Online: https://www.biodiversitylibrary.org/item/43833

DOI: https://doi.org/10.5962/bhl.part.10591

Permalink: https://www.biodiversitylibrary.org/partpdf/10591

\section{Holding Institution}

Smithsonian Libraries

\section{Sponsored by}

Smithsonian

\section{Copyright \& Reuse}

Copyright Status: NOT_IN_COPYRIGHT

This document was created from content at the Biodiversity Heritage Library, the world's largest open access digital library for biodiversity literature and archives. Visit BHL at https://www.biodiversitylibrary.org. 